Alper, T. \& Gillies, N. E. (1958). J. gen. Microbiol. 18, 461-472

\title{
'Restoration' of Escherichia coli strain B After Irradiation: its Dependence on Suboptimal Growth Gonditions
}

\author{
By TIKVAH ALPER AND N. E. GILLIES \\ Medical Research Council, Experimental Radiopathology Research Unit, \\ Hammersmith Hospital, London, W. 12.
}

\begin{abstract}
SUMMARY: After irradiation of Escherichia coli strain B by ultraviolet or ionizing radiations, different plating media give rise to widely different viable counts; the surviving fractions are smallest on media which are optimal for the growth of unirradiated organisms. It is concluded that inhibition of colony formation after irradiation is due in part to an injury which leads to imbalance in the synthetic processes of the cell, so that 'recovery' or 'restoration' may be brought about by suboptimal conditions of growth. The proportion of cell deaths which may be ascribed to this particular injury is determined by the conditions obtaining in bacterial suspensions before and during irradiation, and also by the type of radiation used.
\end{abstract}

There are numerous papers in the literature dealing with modification of radiation damage to micro-organisms by treatment both before and after irradiation. A number of these investigations have been made with Escherichia coli strain B, which appears to be atypical in some respects in its response to radiation, and presumably also in its biochemical behaviour. 'Survival' of micro-organisms after irradiation is commonly defined as the ability to form visible colonies on the surface of solid media; the extent to which $\boldsymbol{E}$. coli B survives, after a given dose of radiation, has been reported as varying with the interval of time between irradiation and plating, the 'incubation medium' before plating, the temperature of incubation after irradiation, and the plating medium (e.g. Roberts \& Aldous, 1949; Stein \& Meutzner, 1950; Heinmets, Lehman, Taylor \& Kathan, 1954). The investigation to be described has been concerned mainly with the effect of the plating medium on the observed survival of $E$. coli B. The results suggest that a single mechanism may underlie the varied means which may be used after irradiation to modify the response of this micro-organism.

\section{ME'THODS}

Media and chemicals. Oxoid 'Blood Agar Base' and Difco 'Nutrient Agar', both obtained as dehydrated granules, were used as plating media. When reconstituted according to the makers' instructions, the former contained: 10 g./l. Lab-lemco meat extract, $10 \mathrm{~g}$./l. Oxoid peptone, $5 \mathrm{~g} . / \mathrm{l} . \mathrm{NaCl}$, and $15 \mathrm{~g} . /$. agar-agar; the latter contained $3 \mathrm{~g} . / \mathrm{l}$. Bacto-beef extract, $5 \mathrm{~g} . / \mathrm{l}$. Bacto-peptone, and 15 g./l. agar-agar. Oxoid Nutrient Broth and Difco Nutrient Broth were also used, which were of the same composition, apart 
from the agar-agar, as Oxoid Blood Agar Base and Difco Nutrient Agar respectively. The $\mathrm{pH}$ values were $\mathbf{7 \cdot 2}$ and $6 \cdot 8$ respectively.

Oxoid $\mathrm{NaCl}$ (Bacteriological grade) and Oxoid Peptone (papain digest of meat proteins) were used for investigations with these media constitutents. The $\mathrm{pH}$ value of Oxoid peptone solution at $10 \mathrm{~g}$./l. was $\mathbf{5 \cdot 6}$.

Buffer solutions were made from chemicals of analytical reagent quality in glass-distilled water. Adjustment of $\mathrm{pH}$ value was made by adding acetic acid or sodium hydroxide. Tests showed that the addition of these compounds to the media was without effect on irradiated bacteria except in so far as they changed the $\mathrm{pH}$ value.

Organisms used. Escherichia coli strain B; E. coli strain B/r; E. coli strain K12 (W 1485: methionine-requiring); E. coli strain ' 86 '; Shigella flexneri strain Y6R; Salmonella typhimurium strain LT2.

Preparation of bacteria for irradiation. Stocks of organisms were routinely maintained on slopes of Oxoid nutrient agar, and subcultured into Oxoid nutrient broth, which was incubated overnight without aeration when bacteria in the stationary phase were required. The yield from such cultures was $10^{8}-10^{9}$ organisms $/ \mathrm{ml}$. When suspensions of bacteria in the logarithmic phase were required, these were obtained by growing the organisms for short periods at $37^{\circ}$ under the moderate aeration provided by the rotation of McCartney bottles on a turntable. $\mathbf{0 . 2} \mathrm{ml}$. of an overnight broth culture was inoculated into $5 \mathrm{ml}$. broth, which was incubated in this way for $1.5 \mathrm{hr}$. From this culture $\mathbf{0 . 2} \mathbf{m l}$. was inoculated into a fresh McCartney bottle containing $5 \mathrm{ml}$. broth, which was rotated in the incubator for $1 \cdot 7 \mathrm{hr}$. The suspensions were centrifuged and washed three times in $0.067 \mathrm{M}$-phosphate buffer $(\mathrm{pH} 6.9)$ and finally resuspended in buffer. Suitable dilutions of organisms for irradiation were made with this phosphate buffer, the maximum concentration used for u.v.irradiation being $6 \times 10^{5}$ organisms $/ \mathrm{ml}$. With X-rays more concentrated suspensions (up to $10^{7}$ organisms $/ \mathrm{ml}$.) were used when it was desired to follow survival down to $10^{-4}$ of the controls.

Plating. Comparisons between different media were made by dispensing samples of suitable dilution from the same irradiated or control suspensions on to agar plates and spreading the fluid over the surface. The samples were delivered by dropping pipettes tipped with platinum tubing, external diameter $0.95 \mathrm{~mm}$., drop size $0.017 \mathrm{ml}$. A sufficient number of drops, up to a maximum of 25, was delivered to give a count of 100-200 colonies/plate. Two or more plates were used to determine the survival after each dose of radiation.

In some experiments volumes of control and irradiated suspensions were delivered to the surface of pieces of cellophan, about $4 \mathrm{sq} . \mathrm{cm}$. in area, which had been laid on the surface of the media under test. As it was convenient to add only small volumes to the cellophan, these volumes were applied by means of 'Agla' microsyringes (Burroughs Wellcome and Co. London), used without needles. The drops, varying from 0.001 to $0.005 \mathrm{ml}$. in size as required, came away cleanly when the pieces of cellophan were touched to the ground-glass tips of the syringes, which had been treated with silicone grease. The drops 
were spread to within 2 or $3 \mathrm{~mm}$. of the edge of the cellophan. After incubation on solid medium colony counts on the cellophan corresponded, volume for volume, with those made directly on the agar surfaces. The standard deviation for any count was the same with both techniques, about $\sqrt{ } 2 n$ for a count of $n$ colonies; the confidence limits indicated in the diagrams represent twice the standard error in each count.

Methods and sources of irradiation. The absolute doses of radiation received by the suspensions were not determined very accurately, as experiments usually involved comparisons of viable counts on different media for samples taken from the same vessel. Radiation dose rates were constant throughout all experiments. Comparisons of the effects of different treatments before or after irradiation were usually made by studying 'dose effect' or 'survival' curves.

Ultraviolet radiation. The source was a water-jacketed Hanovia 'Germicidal' lamp, $15 \mathrm{~W}$., with $85 \%$ of the emitted energy at $2537 \AA$. (maker's figure). Irradiations were carried out in a standard position, $74 \mathrm{~cm}$. from the lamp, the energy being $3 \cdot 3 \mathrm{ergs} / \mathrm{mm} .{ }^{2} / \mathrm{sec}$, as measured by a photocell very kindly calibrated by Dr R. Latarjet. Suspensions were irradiated from above in open glass vessels with optically flat bases, for times varying from $6 \mathrm{sec}$. to 4.5 min. When cultures were compared which had been treated differently before irradiation, they were irradiated side by side in identical vessels.

$X$-rays. A 'Stabilivolt' set, with a Philips 'Metalix' tube was used at $200 \mathrm{kV}, 6 \mathrm{~mA}$, with external filtration of $2 \mathrm{~mm}$. Al and $1 \mathrm{~mm}$. glass. Since sensitivity to ionizing radiation is markedly affected by oxgen concentration, the gas bubbling technique of Ebert (1955) was always used. During irradiation either oxygen or oxygen-free nitrogen was passed in a stream of fine bubbles through the suspensions, which had previously been equilibrated with the appropriate gas. The special type of vessel used has previously been described (Alper, 1955; Howard-Flanders \& Alper, 1957). The dose rate in the vessel was $2000 \mathrm{rads} / \mathrm{minute}$ as determined by ferrous-ion actinometry (Miller \& Wilkinson, 1952).

Neutrons. These were produced by a Van de Graaff generator, from the reaction of $1.8 \mathrm{MeV}$. deuterons with a beryllium target. The generator and the methods of dosimetry have been described by Howard-Flanders (1956) and the details of the method of irradiating bacterial suspensions by HowardFlanders \& Alper (1957).

\section{RESULTS}

In the course of an investigation on the sensitivity of Escherichia coli strain B to $\mathrm{X}$-rays, it was found that viable counts after given doses of radiation were higher on Difco Bacto-nutrient agar than on Oxoid Blood Agar Base, the difference in number increasing with dose; thus the radiosensitivity appeared greater when the Oxoid medium was used. Colony counts on the control (unirradiated) suspensions were the same on the two media, but the colonies on the Oxoid Blood Agar Base were considerably larger and of different morphology. Differences in the slopes of survival curves were found also 
with other types of radiation, viz. neutrons and u.v.-radiation, but not after treatment by exposure to a temperature of $52^{\circ}$ (Fig. 1) or to $0 \cdot 6 \%(\mathrm{w} / \mathrm{v})$ phenol. As shown by Figs 2-4, the ratios of the slopes of survival curves after irradiation varied with the type of radiation, the age of the culture, and, when ionizing radiation was used, with the oxygen concentration in the suspending buffer (Alper \& Gillies, 1957).

Initially it was thought that the underlying phenomenon might be a radiation-induced biochemical need, which was supplied by constituents of the Difco medium, but not by the Oxoid medium. This would have accorded with some aspects of the interpretation placed on their results by Stapleton,

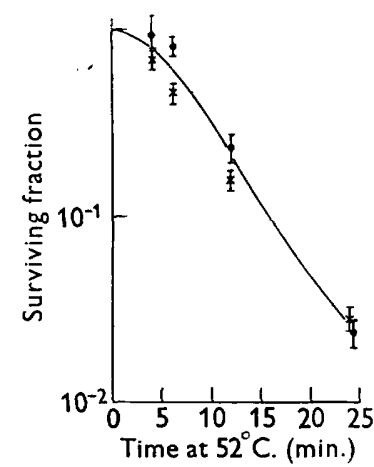

Fig. 1

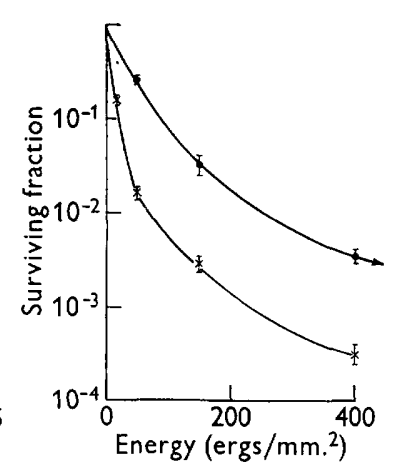

Fig. 2

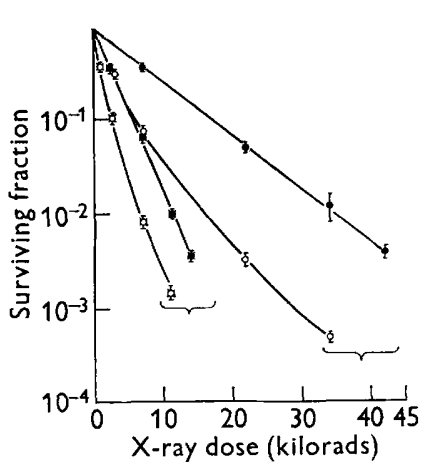

Fig. 3

Fig. 1. Survival of Escherichia coli strain B (stationary phase) after exposure to temperature of $52^{\circ} \mathrm{C} . \times$, Oxoid agar;, Difco agar.

Fig. 2. Survival of Escherichia coli strain B (stationary phase) after exposure to ultraviolet light. $\times$, Oxoid agar;, Difco agar.

Fig. 3. Survival of Escherichia coli strain B (stationary phase) after exposure to X-rays under oxygenation and under anoxia. O, Irradiated under anoxia, plated on Difco agar; $O$, irradiated under anoxia, plated on Oxoid agar; $\not$, irradiated under oxygenation, plated on Difco agar; $\alpha$, irradiated under oxygenation, plated on Oxoid agar.

Sbarra \& Hollaender (1955), working with Escherichia coli $\mathrm{B} / \mathrm{r}$, and by Ellison, Erlanger \& Allen (1955), who found that the addition of sodium acetate to the plating medium increased the viable counts after irradiation of $\boldsymbol{E}$. coli $\mathbf{B}$ and Corynebacterium bovis.

However, there was no increase in the surviving fraction on Oxoid Blood Agar Base supplemented with yeast extract, whole blood, or fractions prepared from the constituents of the Difco nutrient agar. On the contrary, viable counts on the Difco nutrient agar were decreased when it was supplemented by Oxoid broth granules, or by a dialysate prepared from these. The residues of Oxoid broth after dialysis were set with agar, and viable counts on this medium approximately equalled those on unsupplemented Difco nutrient agar (Fig. 5). The increased sensitivity made evident by plating on the Oxoid Blood Agar Base could therefore be regarded as a positive action on the irradiated organisms of one or more dialysable constituents of that medium, so that their absence from the Difco medium promoted 'recovery'. 


\section{Dialysable substances effective in decreasing viable counts after irradiation}

As the Oxoid Blood Agar Base contains $5 \mathrm{~g}$. $\mathrm{NaCl} / \mathrm{l}$., the effects of adding $\mathrm{NaCl}$ to Difco nutrient agar were investigated. When it was found that addition of $\mathrm{NaCl}$ decreased the viable counts after irradiation, the effectiveness of the cation and anion were tested separately. The addition of $0.085 \mathrm{M}-\mathrm{Na}_{2} \mathrm{HPO}_{4}$ / $\mathrm{KH}_{2} \mathrm{PO}_{4}$ ( $\mathrm{pH} \mathrm{7 \cdot 0}$ ) to Difco nutrient agar was without effect. Chloride ion, on the other hand, was equally effective when introduced in equimolar concentration as $\mathrm{NH}_{4} \mathrm{Cl}, \mathrm{KCl}$ or $\mathrm{NaCl}$ (Fig. 6).

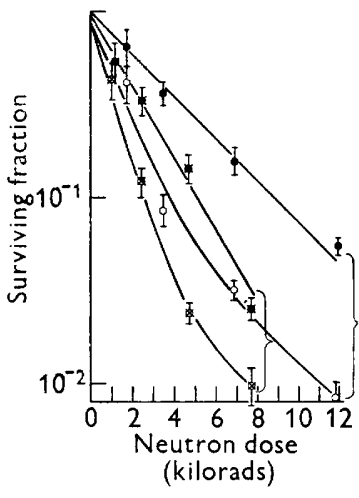

Fig. 4

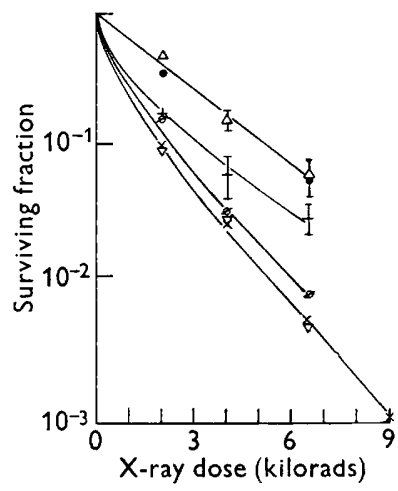

Fig. 5

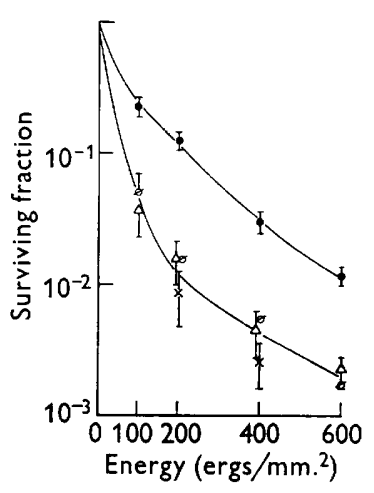

Fig. 6

Fig. 4. Survival of Escherichia coli strain B (stationary phase) after exposure to neutrons under oxygenation and under anoxia. (12\% of the radiation dose was contributed by $X$-rays.) , Irradiated under anoxia, plated on Difco agar; $O$, irradiated under anoxia, plated on Oxoid agar; $\not<$, irradiated under oxygenation, plated on Difco agar; $\$$, irradiated under oxygenation, plated on Oxoid agar.

Fig. 5. Survival of Escherichia coli strain B (stationary phase) after exposure to X-rays under oxygenation. $\bullet$, Difco agar; +, Difco agar $+\mathrm{NaCl}, 5$ g. $/ 1 . ; \nabla$, Difco agar + Oxoid broth granules, 25 g. $/ 1$.; $\varnothing$, Oxoid agar +Difco broth granules, 8 g./1.; $\triangle$, Oxoid broth, residue after dialysis, set with agar-agar; $\times$, Oxoid agar.

Fig. 6. Survival of Escherichia coli strain B (stationary phase) after exposure to ultraviolet light. Difeo agar; $\triangle$, Lab-lemco, $10 \mathrm{~g} . / 1 .+$ peptone $10 \mathrm{~g} . / 1 .+\mathrm{KCl}(\mathbf{0 . 0 8 5} \mathrm{M})$; $\varnothing$, Lab-lemco, $10 \mathrm{~g} . / \mathrm{l}$. + peptone $10 \mathrm{~g} . / 1 .+\mathrm{NH}_{4} \mathrm{Cl}(0 \cdot 085 \mathrm{M}) ; \times$, Oxoid agar, i.e. Lablemco $5 \mathrm{~g} . / 1 .+$ peptone $10 \mathrm{~g} . / 1 .+\mathrm{NaCl}(0.085 \mathrm{M})$.

However, the total action of the Oxoid Blood Agar Base could not be accounted for by chloride alone (Fig. 5). A dialyzable factor was found to be associated with peptone, which was present in higher concentration in the Oxoid than in the Difco medium (Fig. 7). When both peptone $10 \mathrm{~g}$./l. and $\mathrm{NaCl} 5 \mathrm{~g}$./l. were added to the Difco nutrient agar, and the $\mathrm{pH}$ value raised to that of Oxoid Blood Agar Base, survival curves were the same as those observed by plating on the Oxoid medium. The active factor dialysable from peptone has not yet been identified.

\section{The effect of hydrogen-ion concentration}

Since the Oxoid Blood Agar Base was at a higher $\mathrm{pH}$ value than the Difco nutrient agar, this parameter was investigated. The results of two experiments have been combined $\mathrm{n}$ Fig. 8, which shows the surviving fraction, after 
$50 \mathrm{ergs} / \mathrm{mm} .{ }^{2}$ of u.v. radiation, for samples plated on: (1) Difco nutrient agar, at its usual concentration of $8 \mathrm{~g}$. nutrients/l.; (2) Difco nutrient agar, with nutrients at $20 \mathrm{~g} . / 1$. (to match the concentration of nutrients in the Oxoid medium); (3) Difco agar, with 8 g. nutrients/l. + Oxoid peptone 10 g./l.; (4) Difco agar, with nutrients at $8 \mathrm{~g} . / \mathrm{l} .+\mathrm{NaCl}, 5 \mathrm{~g} . / \mathrm{l} . ;$ (5) Oxoid Blood Agar Base (nutrients 20 g./l., $\mathrm{NaCl} 5$ g./l.). The surviving fractions differed somewhat in the two experiments, so they have been combined for presentation in one figure by

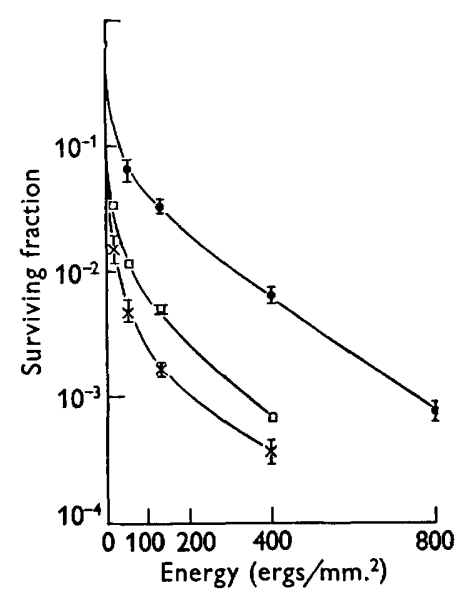

Fig. 7

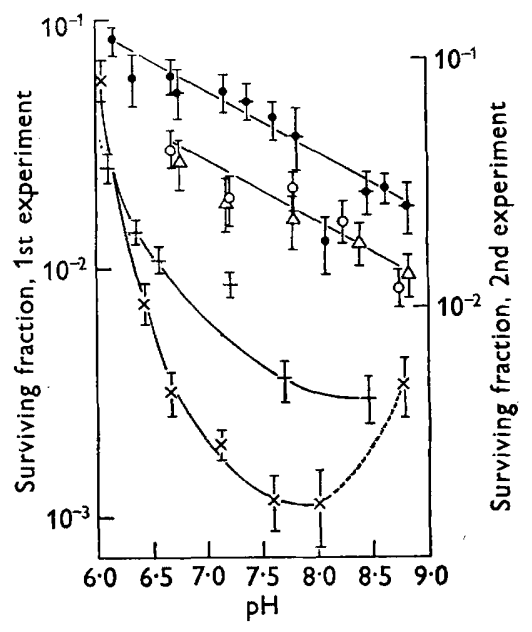

Fig. 8

Fig. 7. Survival of Escherichia coli strain B (logarithmic phase) after exposure to ultraviolet light. O, Difco agar; $\square$, Difco agar + dialysate of peptone, $\mathrm{pH} 7 \cdot 3 ; \times$, Oxoid agar.

Fig. 8. Variation with $\mathrm{pH}$ in surviving fraction of Escherichia coli strain $\mathbf{B}$ (logarithmic phase) after exposure to $50 \mathrm{ergs} / \mathrm{mm} .^{2}$ ultraviolet light. 1 st experiment: 0 , Difco nutrient broth, $8 \mathrm{~g} . / \mathrm{l}$. + agar-agar; +, Difco nutrient broth $8 \mathrm{~g} . / \mathrm{l}+\mathrm{NaCl}, 5 \mathrm{~g} . / \mathrm{l} .+$ agar-agar; $\times$, Oxoid nutrient broth + agar-agar. 2nd experiment: - , Difco nutrient broth, 8 g./l.; $O$, Difco nutrient broth + peptone, $10 \mathrm{~g} . / 1 . ; \triangle$, Difco nutrient broth, $20 \mathrm{~g} .1$.

displacing the ordinate scale applying to the second experiment so that the two Difco nutrient agar curves coincide. It can be seen that for all the media tested, the surviving fraction decreased with increasing $\mathrm{pH}$ value. The curve for Difco nutrient agar + extra peptone is parallel with that for ordinary Difco nutrient agar, showing that the enrichment by peptone decreased the surviving fraction by a constant fraction, whatever the $\mathrm{pH}$ value. The increase in the surviving fraction on the Oxoid media at high $\mathrm{pH}$ values may be associated with the fact that precipitates formed in these on autoclaving, with a possible removal of limiting nutritional factors. The control counts on these two media were lower than on all the others, which did not differ from each other significantly. Control counts on the Oxoid media at $\mathrm{pH} 8 \cdot 1$ and $8 \cdot 8$ were respectively 61 and $42 \%$ of the mean for all other media. The control counts observed on the two media in question were used in estimating the surviving fraction.

The dependence of the survival of irradiated Escherichia coli strain B organisms on the $\mathrm{pH}$ value of the plating medium was reported by Weather- 
wax (1956), who also found that the survival was considerably greater on acid than on alkaline media.

Figure 9 illustrates full survival curves for bacteria which had been harvested in the stationary phase of growth. The highest survival was observed on Difco nutrient agar at $\mathrm{pH} 6 \cdot 15$ although it was supplemented with Oxoid peptone $10 \mathrm{~g} . / 1$. On this medium the colonies grew very slowly and were large enough to count only after incubation for $60 \mathrm{hr}$. at $37^{\circ}$.

The possibility of a genetic origin for the effect of medium on viable count after irradiation

Since the Oxoid Blood Agar Base was used for the routine culture of Escherichia coli strain B, it was necessary to examine whether some form of selection might be responsible for the differences in viable counts after irradiation. The strain was carried through six passages on Difco Bacto-agar and Difco Bacto-nutrient broth; irradiation of these cultures by X-rays or ultraviolet light gave the same results as those observed with routine cultures. The possibility was envisaged that a radiation-induced mutation of a biochemical nature might express itself as inhibition of colony formation on the Oxoid Blood Agar Base. After a dose of $c .6000$ rads of X-rays, there were $10 \%$ survivors on Difco nutrient agar, but only $1 \%$ on Oxoid Blood Agar Base. Difco nutrient agar plates bearing about 150 colonies each, which represented this surviving fraction, were replicated by the technique of Lederberg \& Lederberg (1952) on to fresh Oxoid Blood Agar Base plates. If the differences between viable counts on the two media were due to the induction of mutants unable to grow on the Oxoid medium, it might be expected that only about 15 colonies/Difco nutrient agar plate would be replicated on the Oxoid medium. However, every colony on the Difco plates was reproduced on Oxoid medium.

\section{The time involved in inhibition of colony formation by chloride and the peptone factor}

Since irradiated bacteria seeded on Difco nutrient agar gave rise to daughters able to form colonies on Oxoid Blood Agar base, though the irradiated bacteria themselves could not do so, it was of interest to see at what stage this transition occurred. Samples of control and irradiated suspensions were plated on cellophan squares laid on the surfaces of Difco or Oxoid nutrient agar plates previously warmed to $37^{\circ}$. At given times thereafter, squares were transferred from the initial plates to fresh plates of the same medium and the other medium. The squares transferred soon after plating gave rise, after incubation, to colony counts typical of the second medium, while those which were transferred late gave rise to counts typical of the first medium; intermediate transfers gave rise to intermediate counts, as shown by Fig. 10. Simultaneously with the transfers, the rate of growth in these conditions was studied by removing pieces of cellophan at intervals, shaking vigorously in phosphate buffer and making viable counts. The experiment illustrated by Fig. 10 was carried out at $32^{\circ}$ in order to prolong the lag phase. The period during which the 
colony count could change on transfer appeared to last until the first division had taken place; in some experiments changes occurred even after this, particularly with the transfers from Oxoid to Difco nutrient agar. Weatherwax (1956) carried out analogous experiments, in which changes in the $\mathrm{pH}$ value of the medium were effected at various times after plating. This author considered that the colony-forming ability of irradiated cells was determined at about the time of their first division. It is obviously of great importance to determine the precise time after which change can no longer occur; further experiments under more rigorous conditions are planned.

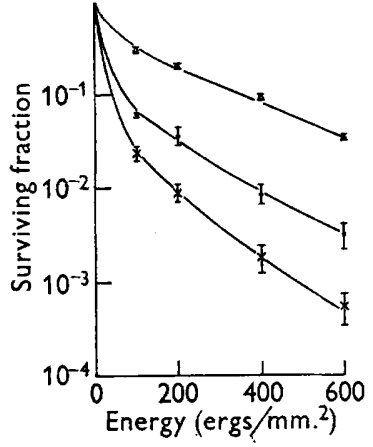

Fig. 9

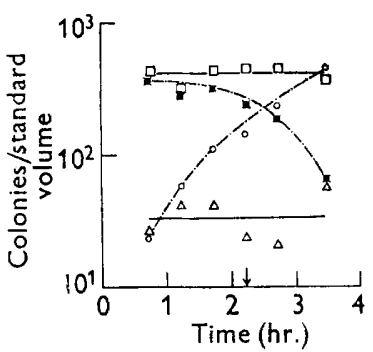

Fig. 10

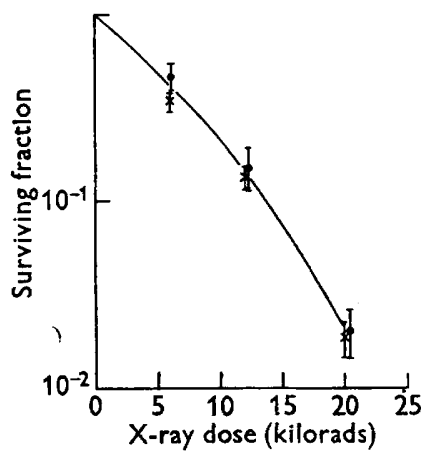

Fig. 11

Fig. 9. Survival of Escherichia coli strain B (stationary phase) after exposure to ultraviolet light., Difco agar, pH 6.8; $\triangle$, Difco agar + peptone, $10 \mathrm{~g} . / 1 ., \mathrm{pH} 6 \cdot 1 ; \times$, Lab-lemco $10 \mathrm{~g} . / 1 .+$ peptone $10 \mathrm{~g} . / 1 ., \mathrm{pH} 7 \cdot 5$.

Fig. 10. The effect of transferring Escherichia coli strain B (stationary phase) from one medium to another at varying times after 2000 rads of $X$-rays under oxygenation. Plates incubated at $32^{\circ}$ C. $\square-\square$, Bacteria seeded on Difco agar plates, transferred to fresh Difco agar plates; $\triangle-\triangle$, bacteria seeded on Oxoid agar plates, transferred to fresh Oxoid agar plates; $\mathrm{O} \cdot-\cdot \mathrm{O}$, bacteria seeded on Difco agar plates, transferred to fresh Oxoid agar plates; $\$ .-$. bacteria seeded on Oxoid agar plates, transferred to fresh Difeo agar plates. The arrow points to the end of lag phase on Oxoid at $32^{\circ}$.

Fig. 11. Survival of Escherichia coli $\mathrm{K} 12$ (methionine-requiring variant) after exposure to $\mathrm{X}$-rays under oxygenation. Difeo agar; O, Oxoid agar.

Incubation of plates at temperatures near $30^{\circ}$ resulted in rather smaller surviving fractions than those observed from plates incubated at $37^{\circ}$, in agreement with the observations on Escherichia coli strain B made by Anderson (1951).

Other bacteria. Various other strains were tested for survival on the Difco and Oxoid media after irradiation. Equal viable counts on the two media were obtained with Escherichia coli strain B/r, E. coli 86, Shigella flexneri Y $6 R$, and a methionine-requiring strain of $E$. coli $\mathrm{K} \mathrm{12}$, all in the stationary stage. The results with the last mentioned organism were of particular interest. As both media were 'complete', it was thought immaterial that the organisms were unable to synthesize methionine. As it happened, the strain grew on the Oxoid Blood Agar Base at a rate comparable with the other $E$. coli strains used; on the Difco nutrient agar, however, the growth was very slow and 
colonies could be counted only after $48 \mathrm{hr}$. of incubation. Nevertheless, the survival curves from counts on the two media were identical (Fig. 11).

A report on the effect of the plating medium on the numbers of biochemical mutants observed after u.v.-irradiation of Salmonella typhimurium (Witkin, 1956) prompted a trial of this organism. The radiosensitivity observed by plating on Oxoid Blood Agar Base was larger than on Difco nutrient agar, the ratios of the slopes of the survival curves being $1 \cdot \%$. With Escherichia coli strain B irradiated in comparable conditions, the ratios of the slopes were about 6 .

\section{DISCUSSION}

The general conclusion which can be drawn from these results is that conditions which are optimal for the growth of unirradiated Escherichia coli strain $\mathbf{B}$ organism are those in which radiation damage, as estimated by viable counts, has its maximum effect. This conclusion is supported by several independent lines of evidence: (a) Preliminary experiments have shown that both unirradiated and irradiated $\boldsymbol{E}$. coli $\mathrm{B}$ have a shorter lag phase and a shorter generation time in Difco broth to which $\mathrm{NaCl}$ has been added than in the unsupplemented Difco broth. (b) A greater degree of survival was observed on media of low $\mathrm{pH}$ value, on which colonies were observed to develop slowly. (c) The increased effectiveness of radiation observed on media containing chloride and/or extra peptone was not maintained at the higher radiation doses. Survival curves changed in slope and tended to run parallel, particularly after u.v.-irradiation, showing that the survivors of the larger irradiation doses were not sensitive to the action of factors in the medium. The change in slope of the survival curve is probably associated with the increased length of lag phase which radiation is well-known to induce in microorganisms. (d) The action of the factors in the medium was much more pronounced with logarithmic than with stationary-stage bacteria; the latter, as is well known, take longer to go into division after re-inoculation.

Nevertheless, not all conditions which slowed growth could protect Escherichia coli strain B organisms after irradiation against factors in the medium; incubation of this strain at suboptimal temperatures did not promote 'recovery', in contrast to the observations made by Stapleton, Billen \& Hollaender (1953) on other strains of E. coli. Furthermore, with other micro-organisms the imposition of sub-optimal conditions did not necessarily bring about 'recovery', as shown by the experiment with $E$. coli K 12 .

Numerous investigations have been reported which deal with modification of the radiation response of micro-organisms by the post-irradiation treatment. The majority of these have shown evidence of 'restoration' or ' recovery' in conditions which would normally be regarded as suboptimal for the growth of the organisms (Latarjet, 1943; Roberts \& Aldous, 1949; Stein \& Meutzner, 1950; Anderson, 1951 ; Stapleton et al. 1953; Buzzell, 1956; Barner $\&$ Cohen, 1956), or else in conditions in which a preliminary incubation period was allowed in a medium which permitted some metabolism to occur, but did not provide all the nutrients required for division (Wainwright \& Nevill, 
1955; Heinmets et al. 1954). There appear to be only a few investigations reported in which 'restoration' was associated with the provision of extra metabolism in the planting medium (Stapleton et al. 1955; Ellison et al. 1955). The experiments of Stapleton et al. with Escherichia coli strain B/r cannot be interpreted directly as indicating that the plating medium supplied a biochemical need induced by irradiation. Bacteria which had been grown in nutrient broth showed greater survival when plated on nutrient than on minimal agar, but the extent of the survival of these bacteria was no greater than that of bacteria grown in minimal liquid medium, before irradiation, and plated afterwards on minimal agar. In the experiments of Ellison et al. (1955) 'recovery' was obtained with $\boldsymbol{E}$. coli $\mathrm{B}$ and Corynebacterium bovis when sodium acetate was introduced into the plating medium, a result which the authors interpreted as indicating reversal of radiation damage by this compound. However, they observed that colony growth was slower on the media which contained acetate, which suggests the possibility that their results may have been another manifestation of the association of 'restoration' with suboptimal conditions of growth.

In some of the investigations in which Escherichia coli strain B has been used, certain procedures applied after irradiation have been regarded as promoting restoration per se; for example, incubation at temperatures higher than $37^{\circ}$ (Stein \& Meutzner, 1950; Anderson, 1951; Buzzell, 1956); incubation in a basal medium before plating on nutrient agar (Barner \& Cohen, 1956). However, the phenomenon of restoration may perhaps be described with a somewhat different emphasis if it be considered that such procedures before plating are of a nature to slow down metabolism and so protect the irradiated bacteria against the action of the peptone factor in the plating medium, and the chloride, where this was added (Buzzell, 1956; Barner \& Cohen, 1956). Barner \& Cohen observed an increase in viable counts with u.v.-irradiated $E$. $\operatorname{coli} \mathrm{B}$, when successive samples from a minimal liquid medium were plated on Difco nutrient agar containing $5 \mathrm{~g}$. $\mathrm{NaCl} / \mathrm{l}$. This can be regarded as analogous with our transfer experiments (Fig. 10), in which a rise in viable count was observed during the first few hours after plating when cellophan squares were transferred from Difco nutrient agar to Oxoid Blood Agar Base; bacteria transferred early were susceptible to the action of $\mathrm{NaCl}$ and the peptone factor, but later they were no longer affected by these substances.

It has been suggested by various authors that the failure of micro-organisms to form colonies after irradiation may be attributed in part to an imbalance in their synthetic processes (Heinmets \& Kathan, 1954; Heinmets et al. 1954; Latarjet, 1954; Barner \& Cohen, 1956). Laterjet (1954) described restoration by certain procedures, such as the action of visible light, as 'restoration by superimposed injury', the latter being of a nature to slow up certain metabolic processes and so prevent the imbalance from occurring. Our results with Escherichia coli strain B support the view that growth of an unbalanced nature is responsible for a part of the lethal effects of radiation on microorganisms, and it is this part which is sensitive to the growth conditions after irradiation. It is convenient to postulate that radiation inflicts damage at 
different sites in the cell, so that the total cell death may be attributable to a variety of mechanisms. It has been shown elsewhere that the ratios between surviving fractions on different media were considerably higher after u.v.irradiation than after ionizing radiation, and, with the latter, the ratios were higher when the irradiations were performed in anoxic than in aerobic conditions (Alper \& Gillies, 1957). It is clear that when u.v.-radiation is used, a large proportion of cell deaths may arise from the particular type of damage which leads to unbalanced growth, but this type may not become manifest when post-irradiation conditions are such as to inhibit the unbalanced growth. With ionizing radiations used in aerobic conditions, however, a considerably larger proportion of deaths is due to the absorption of energy in other sites. This latter proportion will appear larger still if after ionizing radiation the conditions are such that the development of unbalanced growth is inhibited. In general, the particular set of experimental conditions used in any irradiation experiment will determine which mechanism of cell death appears to play the most important role.

We are grateful for gifts of strains from Dr G. E. Stapleton (Escherichia coli strain B/r); Dr W. Hayes (E. coli B and E. coli K 12/W 1485); Dr R. Clowes (Salmonella typhimurium type LT2). We are greatly indebted to Mr D. Moore for his cooperation in carrying out the irradiations and dosimetry with the Van de Graaff generator.

\section{REFERENCES}

AlPER, T. (1955). Bacteriophage as indicator in radiation chemistry. Radiation Res. 2, 119.

Alper, T. \& Gillies, N. E. (1957). The dependence of the observed oxygen effect on the post-irradiation treatment of micro-organisms. Nature, Lond. (in the Press).

Anderson, E. H. (1951). Heat reactivation of ultraviolet inactivated bacteria. J. Bact. 61, 389.

Barner, H. D. \& Cohen, S. S. (1956). The relation of growth to the lethal damage induced by ultraviolet irradiation in Escherichia coli. J. Bact. 71, 149.

Buzzell, A. (1956). The interrelationships between ultraviolet irradiation and the thermal reactivation of Escherichia coli B. Arch. Biochem. Biophys. 62, 97.

EBERT, M. (1955). Hydrogen peroxide production under varying conditions of irradiation. In Radiobiology Symposium 1954, Proceedings of the Symposium held at Liège August-September 1954, pp. 30-8. Ed. Z. M. Bacq \& P. Alexander, London: Butterworths.

Eluison, S. A., Erlanger, B. F. \& Allen, P. (1955). The chemical reversal of ultraviolet effects on bacteria. J. Bact. 69, 536.

Heinmets, F. \& Kathan, R. H. (1954). Preliminary studies on the mechanism of biological action of ultraviolet irradiation and metabolic recovery phenomenon. Arch. Biochem. Biophys. 53, 205.

Heinmets, F., Lehman, J. J., Taylor, W. W. \& Kathan, R. H. (1954). The study of factors which influence metabolic reactivation of the ultraviolet inactivated Escherichia coli. J. Bact. 67, 511.

Howard-Flanders, P. (1956). Factors in the production of intense hydrogen ion beams. Ph.D. Thesis, University of London.

Howard-Flanders, P. \& Alper, T. (1957). The sensitivity of micro-organisms to irradiation under controlled gas conditions. Radiation Res. (in the Press).

G. Microb. xvirI 
LatarJet, R. (1943). Action du froid sur la réparation des radiolésions chez une levure et chez un bactérie. C.R. Acad. Sci., Paris, 217, 186.

LatarJet, R. (1954). Spontaneous and induced cell restorations after treatments with ionizing and non-ionizing radiations. Acta radiol., Stockh. 41, 84.

Lederberg, J. \& Lederberg, E. M. (1952). Replica plating and indirect selection of bacterial mutants. J. Bact. 63, 399.

Miller, N. \& Wilkinson, J. (1952). Actinometry of ionizing radiations. In Radiation Chemistry, Disc. Faraday Soc. no. 12, p. 50.

Roberts, R. B. \& Aldous, E. (1949). Recovery from ultraviolet irradiation in Escherichia coli. J. Bact. 57, 363.

Stapleton, G. E., Billen, D. \& Hollaender, A. (1953). Recovery of X-irradiated bacteria at sub-optimal incubation temperatures. J. cell. comp. Physiol. 41, 345.

Stapleton, G. E., Sbarra, A. J. \& Hollaender, A. (1955). Some nutritional aspects of bacterial recovery from ionizing radiations. J. Bact. 70, 7 .

Stern, W. \& Meutzner, I. (1950). Reaktivierung von UV-inaktiviertem Bakterium coli durch Wärme. Naturwissenschaften, $37,167$.

Wainwright, S. D. \& Mullaney, J. (1953). Some effects of metabolic inhibitors upon survival of ultraviolet irradiated Escherichia coli. Experientia 9, 376.

Wainwright, S. D. \& Nevill, A. (1955). Modification of the biological effects of ultraviolet irradiation by post-irradiation treatment with iodoacetate and peptone. J. gen. Microbiol. $12,1$.

Weatherwax, R. S. (1956). Reactivation of ultraviolet-irradiated Escherichia coli. J. Bact. 72, 329.

Witkin, E. M. (1956). Time, temperature and protein synthesis: A study of ultraviolet-induced mutation in bacteria. Cold Spr. Harb. Symp. quant. Biol. $21,123$. 